\title{
Multilevel marketing: optimizing marketing effectiveness for high-involvement goods in the automotive industry
}

\author{
Thomas Niemand $^{1}$ - Sascha Kraus ${ }^{2}$ (D) - Sophia Mather ${ }^{3}$. \\ Antonio C. Cuenca-Ballester ${ }^{4}$
}

Published online: 16 May 2020

(C) The Author(s) 2020

\begin{abstract}
With a surge in communication channels increasing the complexity of today's media landscape, companies face new challenges concerning the allocation of their advertising budget. As consumers become increasingly more autonomous in gathering information from the channels they deem most suitable, they encounter several touchpoints on their customer journey. Marketers struggle with the assessment of channel effectiveness. Despite a rise in research on the topic of attribution, findings and methodology vary greatly regarding variables and outcomes. The question of how to determine suitable attribution modeling that optimizes advertising effectiveness thus remains unanswered. This article aims at assessing which factors influence channel effectiveness in the context of high-involvement goods. Based on a unique dataset from a multinational car manufacturer, a Structural Vector Autoregressive model has been formulated revealing channel interactions, lagged effects of advertising and conversion funnel stages as being highly influential factors concerning channel effectiveness.
\end{abstract}

Keywords Attribution modeling $\cdot$ Multichannel advertising $\cdot$ Multi-channel attribution modeling $\cdot$ Conversion funnel $\cdot$ Channel effectiveness $\cdot$ Automotive industry

Thomas Niemand

thomas.niemand@tu-clausthal.de

Sascha Kraus

sascha.kraus@durham.ac.uk

Sophia Mather

sophia.mather@hotmail.com

Antonio C. Cuenca-Ballester

antonio.cuenca@uv.es

Extended author information available on the last page of the article 


\section{Introduction}

When one thinks about a journey, it is usually a linear path. A journey from one point to another, from A to B. The same linearity is associated with the term "customer journey." This journey occurs through several touchpoints and devices from the moment a consumer establishes his/her need until the moment he makes a transaction. Each touchpoint has a specific impact, either bringing the consumer closer to or driving him further away from the conversion to become a customer (Batra and Keller 2016).

In the context of multichannel marketing, the number of channels and devices used by consumers to gather information has drastically increased in recent years. Especially online advertising has gained popularity in the last decade and witnessed a massive growth in investment, predicted to account for 335.48 billion U.S. dollars in 2020 (eMarketer 2019). Increasing diversity and complexity of today's communication environment, this emergence of new communication formats challenges media attribution (Gupta and Steenburgh 2008). The challenge of identifying the most effective advertising medium has particularly increased as consumers are exposed to several advertising formats and have become more autonomous in terms of choosing advertising channels. While companies used to push product-related information towards the consumer, today, the opposite is the case. Consumers base their channel choice on factors such as individual preference, costs and benefits of available channels (Hauser and Wernerfelt 1990; Mehta et al. 2003). However, this choice varies over time depending on the consumer's position on the conversion funnel (Valentini et al. 2011). The more the consumer becomes familiar with the considered brand and trusts in its ability to satisfy his/her needs, the more he moves down the funnel towards conversion. As highlighted in previous studies, channel effectiveness might differ according to consumer positioning. Some channels being more attractive to the consumer in the awareness phase, others in the consideration phase (e.g., Shankar et al. 2011). Inter- and intra-media interaction, as well as synergetic effects between channels, also hampers correct attribution per touchpoint, which acts as a guide for budget allocation (e.g., Li and Kannan 2014). The research revealed that while some channels seem ineffective by themselves, they support more efficient ones when used simultaneously (Naik and Raman 2003). With a growing number of channels becoming available, finding the right communication mix manifests itself as being a thorny matter.

Many attempts have been made to tackle the attribution challenge considering the recent changes in advertising, while many companies reportedly still allocate market spending based on past allocations and rules of thumb (Doctorow et al. 2009). For that reason, the Marketing Science Institute has defined attribution modeling as a priority for marketing academia (MSI 2016). Rule-based models built in the absence of suitable methods have given valuable insights into the ability of channels to attract new customers or lead to conversion (Nisar and Yeung 2017). Nevertheless, these heuristic models fail to include all relevant touchpoints having influenced the consumers' decision (e.g., Li and Kannan 2014). The widely used last-touch attribution model (LTA) attributes the full credit for a conversion to the channel that has been used by the consumer right before it ("last touch"), thereby disregarding touchpoints encountered previously (Xu et al. 2014). Despite the rise of disaggregate individual-level tracking data and the recent interest in multichannel attribution, marketers still struggle to 
incorporate all variables influencing advertising effectiveness for channel attribution and budget allocation. While some only focus on a few online channels (e.g., Ghose and Todri-Adamopoulos 2015), others disregard synergies (e.g., Li and Kannan 2014; $\mathrm{Xu}$ et al. 2014; Anderl et al. 2016), fail to incorporate carryover effects between channels (Zantedeschi et al. 2016) or refrain from evaluating channel effectiveness related to distinct conversion funnel stages (e.g., Shao and Li 2011).

We, therefore, extend the current state of research on attribution modeling to incorporate previously raised limitations of existing models regarding the assessment of channel effectiveness, channel synergy and its effect on funnel stages. We further investigate unique advertising data from a high-involvement goods sector - the automotive industry - as previous research mainly considered low-involvement goods. By doing so, we extend the contributions made in low-involvement contexts to a highinvolvement context.

Since advertising effectiveness in the automobile industry is evaluated based on lead generation, the latter is used as the aimed-for outcome. The following research question will be answered in this article: Is attribution modeling a suitable solution for advertising effectiveness optimization in the context of high-involvement goods?

We propose a Structural Vector Autoregressive (SVAR) model that allows for an assessment of channel effects on a specific outcome as well as their interaction between each other and the lagged effect of advertisement in time. This model is estimated using a dataset provided by a leading multinational automotive company containing advertising expenses and traffic per channel for four anonymized brands over one year. We aim at three main contributions to the current research: First, this study verifies previous findings on channel attribution by checking their validity in the present highinvolvement goods sector. Second, we apply an SVAR to this context, investigating as to whether heuristic models (e.g., LTA) perform equally or worse. Third, guidance is provided to researchers and managers by highlighting key factors to consider when focusing on finding an optimal channel mix.

\section{Theoretical framework}

\section{Guiding the customer decision-making process}

\section{Customer journey \& conversion funnel}

Based on the works of cognitive psychologists, marketers started to develop and adopt decision-making processes leading to a so-called conversion funnel (De Haan et al. 2016; Howard and Sheth 1969). With every stage achieved, the conversion of consumers to customers becomes more likely. Sharing links to hierarchy-of-effects models such as AIDA (Kotler and Armstrong 2011), the most popular conversion funnel divides the customer journey into an awareness (upper funnel), a consideration (middle funnel) and a purchase stage (lower funnel) (Jansen and Schuster 2011).

Because each touchpoint along the customer journey affects conversion, companies need to be aware of the different stages within the decision-making process (Batra and Keller 2016). Within the awareness phase, the consumer recognizes his need and explores options that could satisfy this need. In this stage, consumers expect objective 
information about the product/service to build a fundament for decision-making. In the consideration phase, the consumer evaluates and compares the different options. Responsive to more detailed information, he might turn to comparison sites. The final decision is made during the purchase phase when the consumer converts to a customer.

Because of the various customer journeys consumers encounter, decision-making processes may be clustered into low- and high-consideration decisions (Crestodina 2019). Low-consideration decisions, e.g., buying Fast Moving Consumer Goods (FMCG), typically involve a short transaction cycle. Decisions are made easily and quickly without intense information retrieval. Marketers focus on creating awareness through social content and by including influencers. Products or services acquired in this low-consideration set are typically referred to as low-involvement goods. In contrast, high-involvement goods typically require a high-consideration decision, e.g., buying a car, with multiple decision-makers, extensive information research through a multitude of channels with many decision criteria involved. Hence, high-involvement goods require an effortful and long-term decision-making process. Statistics show that $69 \%$ of German consumers start researching three months before their potential car purchase. These consumers spend around ten hours in researching before visiting a retailer or dealer. Further, $60 \%$ of the respondents said they seek advice online. (Deloitte 2018). Overall, the extensive consideration phase provides opportunities for companies but also bears the risk of lowered influence once the consumer has reached the purchase phase and initiates contact with a company (Crestodina 2019).

\section{Promotional mix in marketing along the conversion funnel}

With customer journeys evolving, companies need to adapt by changing their communication strategy and channels accordingly. Companies target potential customers through a mix of offline and online communication channels, the media mix. Previously, companies focused on outbound marketing known as pushing information. Now, they emphasize the importance of attracting consumers through inbound marketing known as pulling consumers (Klever 2009). This approach uses content marketing and search engine marketing (SEM) to offer relevant content and attract attention. Even though, consumers still consult both consumer-initiated communication (CIC) and firm-initiated communication (FIC) through which companies initiate marketing interventions (Bowman and Narayandas 2001; Wiesel et al. 2011). Preferences for CIC or FIC are also time dependent (Valentini et al. 2011). A consumer evaluates each available channel according to its ability to guide him/her to the desired information in the most cost- and time-effective manner (Hauser and Wernerfelt 1990; Mehta et al. 2003). Research empirically confirms that media holds the distinctive abilities needed to elicit a transaction (e.g., Dinner et al. 2014) and that these abilities vary depending on conversion funnel stage (e.g., Shankar et al. 2011). When a need arises, consumers fall back to the channels they previously used to reassess benefits and costs (Hauser and Wernerfelt 1990; Mehta et al. 2003).

Previously, marketers only had a small selection of offline communication channels at their disposal. Television (TV) combined with radio and outdoor ads can reach a broad audience and develop brand salience (Briggs et al. 2005). Hence, these media are most appropriate for the awareness phase. Print ads offer detailed information about a brand's features and are well-suited for mid-funnel nurturing (e.g., Stern and Resnick 
1991). Further, magazines are considered one of the most cost-effective offline media and are very selective (Briggs et al. 2005). Addressing the bottom part of the conversion funnel, newsletter coupons and printed catalogs are examples of traditional media fitting with the purchase phase.

Such traditional offline media continue to be persuasive (Nunes and Merrihue 2007). However, TV remains the leading advertising medium worldwide accounting for around 28\% of global advertising spending by 2021 (Zenith 2019). Digital channels have been gaining in popularity and are predicted to account for $\$ 335.48$ billion (USD) in 2020 (eMarketer 2019). Content and timing personalization, as well as the improved measurement of advertising or channel effectiveness through tracking, facilitate micro and dynamic segmentation and targeting. Hence, these measures enable several novel advantages for digital channels (Smith et al. 2006). Online advertisers track behaviors using cookies. By identifying specific behavioral traits, the advertiser retargets consumers in case he/she leaves the product/service website without completing a transaction. This concept is known as behavioral targeting. Via target ads based on different criteria (contextual, semantic, geographical retargeting), website traffic and the conversion rate are increased (Danaher et al. 2010; Hoban and Bucklin 2015). While search ads are only being displayed in the sponsored section of a search result page, display ads are depicted when the targeted consumer surfs on unrelated websites. Due to the negative and nonlinear effect of repeated exposures to a display ad (Chatterjee et al. 2003), targeting requires precise tracking and implementation of display ads (Braun and Moe 2013; Lambrecht and Tucker 2013; Schumann et al. 2014). Search ads, on the other hand, are an appropriate medium to target consumers in the awareness phase. Several studies have highlighted that paid search ads impact click-through and conversion rates positively (Berman and Katona 2013; Jerath et al. 2014; Rutz and Bucklin 2011).

However, effectiveness depends on the controllability of a channel, that is, owned and earned media (e.g., Danaher et al. 2006; Steenkamp and Geyskens 2006). In owned media, content is produced by the company itself (e.g., websites, blogs) while in earned media, content is produced by others such as the users (e.g., social media content of other consumers). Owned media enables specific content to create interest and introduce the company's offer into a consumer's consideration set. Owned social media has been identified as being a decisive impact factor to customer spending, profitability and cross-buying through its valence, receptivity and customer susceptibility (Kumar et al. 2016; Schweidel and Moe 2014). Van den Bulte and Wuyts (2007) highlight online communities, blogs, and social networks as being the leading social media platforms enabling users to establish a relationship with a brand. Further, comparing the effectiveness of social media to email, Li and Kannan (2014) discovered that emails cause thrice as many transactions as social media with a $17 \%$ higher average order value. Owned media thus favors the development of informal social networks and complements information provided by the company (Goldenberg et al. 2012).

Regarding earned media, opinions shared from online influencers play a crucial role in shaping customers' preferences and are of great importance to companies (Trusov et al. 2010). Owned and earned media seem to exert influence on brand preference by creating credible content and increasing transactions. Even though digital channels may have a stronger influence on individuals than traditional media, the latter is said to be a fundamental means of encouraging positive effects (Bruce et al. 2012; Gopinath et al. 2014). 
None of these individual communication channels are enough to foster conversion alone. Marketers thus need to not only pay attention to the individual impact of each communication channel (main effect) but also to its role within the communication flow (interaction effects, Batra and Keller 2016). Depending on the media and targeted audience, the content spread through diverse communication channels varies. However, integrating different channels in a communication mix introduces complexity in the assessment of advertising effectiveness.

\section{Advertising effectiveness}

\section{Measurement}

Achieving (or optimizing) advertising effectiveness requires an appropriate outcome variable, termed indicators of advertising effectiveness. These indicators often include return on investment (ROI), return on marketing investment (ROMI), cost per win, cost per lead, conversion rate, incremental sales or customer lifetime value. A channel with a higher indicator (or for cost: lower) should be given more budget, that is, more budget should be allocated to this channel. However, according to a global survey by McKinsey \& Co., companies tend to allocate budgets based on past allocations and rules of thumb rather than quantitative measures regarding indicators of efficiency (Doctorow et al. 2009). A growing body of literature has examined the relationship between investment in advertising and profit.

Online channels contribute to the achievement of increased measurement quality as compared to offline channels (Bonfrer and Drèze 2009). This can be explained by Bass' (1969) challenges of a market being able to a) disentangle the isolated effect of advertising from other effects for a given indicator, b) measure this unit's effect for exposures and indicators and c) separate the (directional) effects of advertising on sales and of sales on advertising. Research shows that precise tracking of online media helps to improve on these challenges as it allows for a time-variant, vast and reliable database. Decades ago, researchers assumed that advertising effectiveness remained constant over time. However, as empirical research has discovered, advertising effectiveness is rather dynamic and varies substantially over time as circumstances, such as the competitive landscape and consumer behavior, change (e.g., Jedidi et al. 1999; Krishnamurthi and Papatla 2003; Mahajan et al. 1980). Particularly online channel data, but traditional data as well, speaks against heuristics, rules of thumb or constant rule sets of allocating budgets and calls for contingent, sensitive empirical models.

\section{Effects}

Looking at ROMI as the only advertising effectiveness indicator leads to numerous relevant factors influencing ROMI including retail availability (Parsons 1974), product quality (Kuehn 1962), size of the sales force (Gatignon and Hanssens 1987), and product maturity (Sethuraman et al. 2011). Even though opinions differ on which of these factors play the most crucial role concerning advertising effectiveness, the majority of researchers in this context seem to agree on the impact imposed by the media context (= conditions in a channel) and media engagement (= interest and responsiveness of consumers in a channel). Additionally, media engagement strongly 
depends on media context because some channels are more or less appropriate for a given type of content (Bushman and Bonacci 2002; Nyilasy et al. 2011). Thus, marketers need to choose the right channel mix to engage consumers and increase their ROMI. Previous literature focused on assessing the effectiveness of traditional types of advertising such as television (Wood and Poltrack 2015) and online advertising (Lewis and Rao 2015) as well as the impact of advertising on sales (e.g., Hu et al. 2007; Leone and Schultz 1980; Sethuraman et al. 2011). As consumers diversify their media consumption, studies highlight that multichannel strategies increase reach (e.g., Briggs et al. 2005; Fulgoni and Lipsman 2014), information credibility (e.g., Chang and Thorson 2004), and synergy of media strengths (e.g., Dijkstra et al. 2005; Tsao and Sibley 2004). By spreading similar content through different channels, marketers benefit from positive interaction effects - synergies - between media and observe growth in the overall advertising effectiveness (e.g., Chang and Thorson 2004). Finally, accuracy and coverage of targeting also increase ROI as advertising effectiveness (Broussard 2016).

Drawing on research regarding multichannel attribution (e.g., Li and Kannan 2014; Xu et al. 2014), optimal budget allocation (e.g., Briggs, et al. 2005; Naik and Peters 2009; Raman et al. 2012), channel effectiveness (e.g., Dinner et al. 2014; Manchanda et al. 2006; Wiesel et al. 2011) as well as channel synergies (Chatterjee 2012; Lin et al. 2013), this article focuses on assessing which factors influence multichannel effectiveness in the automotive industry. Studies investigating the impact of advertising channels outside of a website (search engine, display ads, email) on conversion also act as a base (e.g., Chan et al. 2011; Chatterjee et al. 2003; Ghose and Yang 2009). Contrary to the previous literature that focused on selected advertising channels, this article incorporates a wide variety of online advertising channels (i.e., referral, paid email, paid search, display ads) and assesses their impact on conversion according to funnel stages (see, e.g., Ansari et al. 2008; Naik and Raman 2003), as called for e.g. by Kannan, Reinartz and Verhof (2016). Even though the psychological component impacting consumer decision-making (Danaher et al. 2006; Moe and Fader 2004) cannot be revealed, this research considers the influence of time, particularly carry-over effects (preceding advertising expenses). Finally, the methodology behind this study is strongly based on Danaher and van Heerde (2018) as well as De Haan et al. (2016) and Pauwels et al. (2016), who stressed that further work is needed to generalize the findings in different contexts. By extending their models and testing them within the automotive industry, this article contributes to the generalizability of their studies' insights (Table 1).

\section{Empirical approach}

\section{Conceptual framework}

Our research framework (see Fig. 1) visualizes the relationship between the effectiveness of multiple online advertising channels on relevant outcomes (lead). We focus on lead generation, i.e. a configured car in an online configurator that is submitted to the manufacturer since an actual purchase cannot be made and thus not tracked online in the present sector. Advertising effectiveness is also being assessed based on organic 


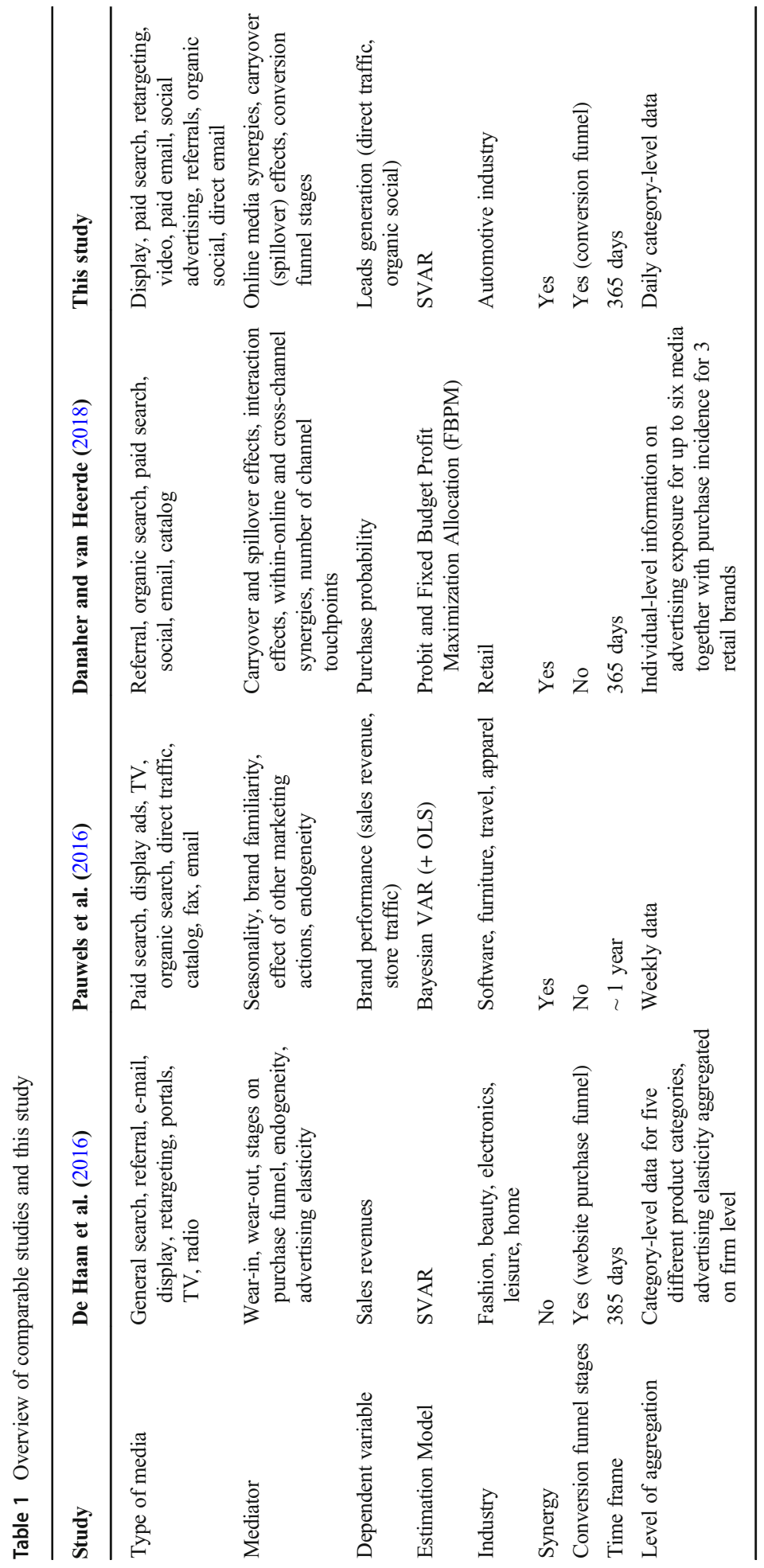


search and direct traffic to increase the insights' generalizability. The framework shows a typical conversion funnel with six stages (awareness, interest, consideration, intent, evaluation, conversion). This funnel has often been analyzed in the marketing literature (De Haan et al. 2016; Howard and Sheth 1969). To fill this funnel with consumers and convert them into leads, marketers use various types of advertising channels. Some of them intended to create awareness while others push permissions further down the funnel. After a first encounter with the brand, the user browses through the website to get information on the provided products and services. The conversion funnel usually starts with a visit on the homepage leading to various product (or model) pages (De Haan et al. 2016). Not being able to purchase a car directly online, the equivalent of a basket in the automotive industry would be a page that generates a lead, i.e., submitting a configurator page. As discussed before, advertising varies in its effect on consumers based on the type of communication channel used (Batra and Keller 2016; Nisar and Yeung 2017), other simultaneous communication channels (e.g., Naik and Raman 2003) and the purchase funnel stage on which the target is currently situated (Luo and Donthu 2006; Osinga et al. 2011; Reid et al. 2005). Despite communication forms having drastically increased with the rise of online advertising, marketers are still struggling to assess channel effectiveness and allocate marketing budgets accordingly. It is, therefore, necessary to assess which variables influence channel effectiveness in the context of high-involvement goods.

In this context, a growing body of literature focuses on analyzing the mediators between advertising and outcomes. Many authors highlight the existence of synergy effects between certain advertising channels, thereby mainly focusing on low-stake decisions (e.g., Lemon and Nowlis 2002; Naik and Raman 2003) and the interaction of few channels (e.g., Dinner et al. 2014; Naik and Peters 2009; Wiesel et al. 2011). Consequently, channel effectiveness in the context of high-involvement goods might also depend on channel interactions.

Moreover, the channel through which a consumer lands on the brand's website combined with subsequent visited pages gives insights into the channel effectiveness depending on the conversion funnel stage. Consumers also react differently to

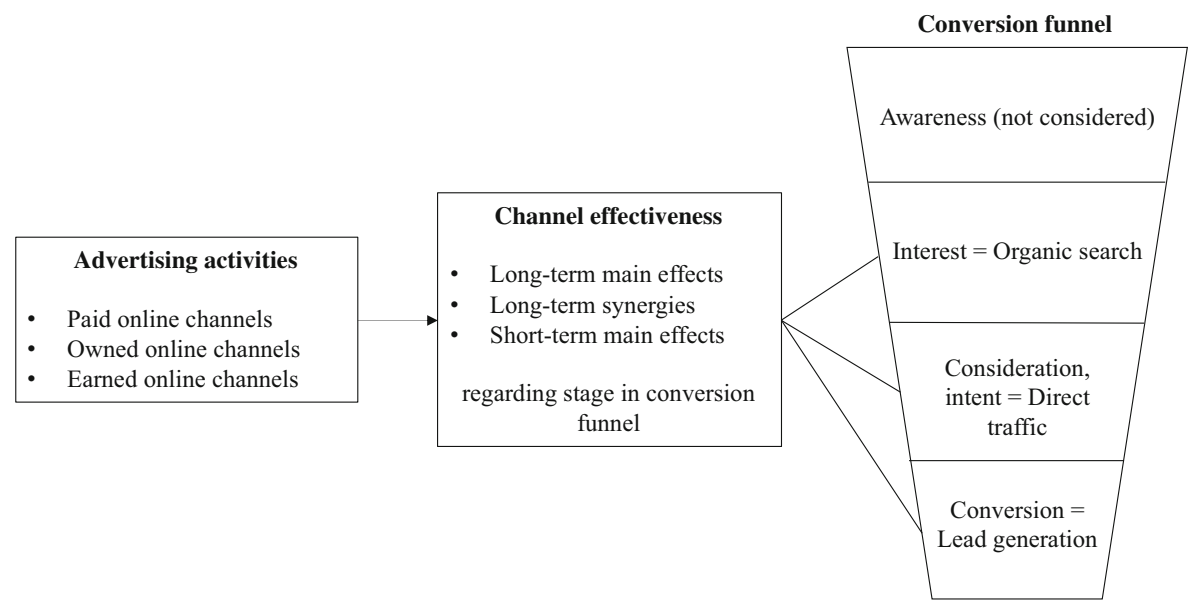

Fig. 1 Conceptual framework 
advertising depending on their level of involvement with the brand (Ansari et al. 2008; Naik and Raman 2003). Hence, this article focuses on identifying if channel effectiveness in the automotive industry varies within the conversion funnel stages.

Moreover, channel effectiveness cannot always be precisely measured and attributed. For example, advertising might influence outcomes in future periods (Leone 1995; Sethuraman et al. 2011). Therefore, this article aims at determining whether carryover effects from previous exposures can be observed. Most of the research on this topic shows moderate amounts of carryover (e.g., Danaher and Dagger 2013; Danaher and van Heerde 2018; Li and Kannan 2014). Due to the long customer journey associated with the purchase of a high-involvement good, higher carryover effects may be observed in the automotive industry. Further, this article investigates as to whether heuristic attribution models are sufficient to establish channel effectiveness.

In line with the low- vs. high-involvement context, most research focuses on lowstake decisions (Ghose and Todri-Adamopoulos 2016; Naik and Raman 2003), while disregarding high-stake decisions. Further, research focusing on high-stake decisions (Li et al. 2019; Li and Kannan 2014) or even more specifically on the automotive industry (Briggs et al. 2005; Naik and Peters 2009), have either only focused on offline or limited online channels. Furthermore, while some fail to incorporate synergies between channels (e.g., De Haan et al. 2016; Raman et al. 2012), others overlook carryover effects (e.g., Danaher and Dagger 2013; Li et al. 2019) or the dependency of advertising effectiveness on purchase funnel stages (e.g., Danaher and van Heerde 2018; Pauwels et al. 2016; Shao and Li 2011). Taken together, focusing, we aim at overcoming these deficiencies and integrating a wider number of online channels with synergies, carryovers and funnel stage contingency.

\section{Dataset and variable operationalization}

Our data is based on the activities of a major international car manufacturer hosting several brands under its umbrella brand and has been retrieved from April 1, 2018, to March 31, 2019, covering 365 days. The data provider positions itself in the mid-range automobile segment and offers several brands that differ in brand identity and target groups. By comparing these brands, we aim to identify further differences in channel effectiveness due to brand positioning. For anonymity reasons, we label these brands as Brand A to Brand D. Brand A offers lower price models for the broader audience with most contacts. Brand B has the second-highest amount of contacts constituted by users with a superior purchasing power than the ones from Brand A. Brand A and B show a similar advertising budget, leaving Brand $\mathrm{B}$ with a higher budget per contact. Brand C's customer base possesses the highest purchasing power among all four brands, but with fewer context than the previous brands. Finally, Brand D accounts for the smallest customer base and the lowest advertising investment.

Currently and through all brands, most of the budget (between 33\% for Brand A and 52\% for Brand D) has been allocated to display advertising. Table 2 divides the data provider's monthly investment by channel and highlights the percentage allocation of the budget through advertising channels. Across all brands, display advertising possesses the highest share of allocation with $42.2 \%$. Around half of the advertising budget is invested in social advertising (19.3\%), video (16.7\%), and paid search (14.4\%). The remaining budget is divided between retargeting (3.7\%) and paid email (3.6\%) activities. 
Table 2 Monthly investment per advertising channel across all brands

\begin{tabular}{lrrrrrr}
\hline Month & Display & Paid search & Retargeting & Video & Paid email & Social advertising \\
\hline April & 902.65 & 297.22 & 61.44 & 315.21 & 72.54 & 325.91 \\
May & 338.71 & 243.70 & 46.70 & 101.34 & 23.40 & 185.19 \\
June & 516.47 & 243.64 & 59.13 & 120.27 & 23.40 & 352.75 \\
July & 626.81 & 246.08 & 45.00 & 152.25 & 24.70 & 222.02 \\
August & 586.61 & 243.58 & 49.29 & 52.25 & 13.00 & 452.39 \\
September & 108.61 & 237.50 & 69.75 & 493.70 & 66.80 & 484.42 \\
October & 751.36 & 229.31 & 47.80 & 438.66 & 108.94 & 316.33 \\
November & 664.79 & 183.41 & 38.00 & 182.13 & 99.07 & 247.58 \\
December & 406.76 & 203.58 & 35.00 & 240.54 & 60.85 & 205.00 \\
January & 687.62 & 199.06 & 43.00 & 255.38 & 42.77 & 310.58 \\
February & 542.52 & 205.00 & 50.00 & 252.27 & 46.28 & 281.77 \\
March & 605.94 & 109.02 & 140.06 & 442.27 & 74.46 & 153.66 \\
Budget allocation & 7716.62 & 2641.09 & 685.17 & 3046.26 & 656.21 & 3537.60 \\
Budget allocation (\%) & $42.2 \%$ & $14.4 \%$ & $3.7 \%$ & $16.7 \%$ & $3.6 \%$ & $19.3 \%$ \\
\hline
\end{tabular}

Notes. All absolute values in $\mathrm{T} €$

Since the data incorporates four brands, it is not restricted to a single campaign, including all advertising activities through different channels that have been undertaken in that period. No single campaign has been detected that could have been compared for all the brands. The consumer's path from channel to channel has been tracked through cookies.

Table 3 provides an overview of the variable operationalization. Our data comprises 1460 data points (= 365 days * 4 brands) with monthly expenditure per channel and brand. Online advertising channels include paid (display, paid search, retargeting, paid email, social advertising), owned (video, direct email) and earned channels (organic social, referral). In addition to distinguishing the channels into paid, owned and earned media, we differentiate between customerinitiated communication (CIC, i.e., retargeting, referrals, organic social) and firm-initiated communication (FIC, i.e., display, paid search, paid email, social advertising, video and direct email) as often used in previous research ( $\mathrm{Li}$ et al. 2017; Wiesel et al. 2011). Referrals (e.g., news website reporting about a campaign) can be classified as either FIC or CIC since neither the company nor the consumer initiated the contact (Anderl et al. 2015). We assume it to be CIC as many automotive-related websites exist that likely function as referrals. It is noted that direct email refers to a free of cost channel since no external provider is required as with paid email.

Following De Haan et al. (2016), we designate the top of the funnel as interest, the middle of the funnel as interest and consideration and the bottom of the funnel as conversion. Further, we acknowledge that the awareness stage cannot be quantified in online channel data (awareness needs to be generated before clicking visiting a homepage for the first time). We further designate a started lead as the equivalent of the basket on retailer websites and a submitted lead as the equivalent 
Table 3 Variable operationalization

\begin{tabular}{|c|c|c|}
\hline Criterion & Variables & Operationalization \\
\hline \multirow[t]{9}{*}{ Advertising channels } & Display & Daily cost of display \\
\hline & Paid search & Daily cost of search engine advertising \\
\hline & Retargeting & Daily cost of retargeting \\
\hline & Video & Daily cost of video \\
\hline & Paid email & Daily cost of paid email \\
\hline & Social advertising & Daily cost of social advertising \\
\hline & Referrals & Daily visits through unpaid referring domains \\
\hline & Organic social & Daily visits through unpaid social interaction \\
\hline & Direct email & Daily visits through direct email \\
\hline \multirow[t]{3}{*}{ Conversion funnel } & $\begin{array}{l}\text { Top of the funnel: } 1 . \text { Interest } \\
=\text { Organic search }\end{array}$ & $\begin{array}{l}\text { 1. Daily number of first-time visits } \\
\text { through organic search }\end{array}$ \\
\hline & $\begin{array}{l}\text { Middle of the funnel: 2. Consideration, } \\
\text { intent }=\text { Direct traffic }\end{array}$ & $\begin{array}{l}\text { 2. Daily number of direct traffic on } \\
\text { model page }\end{array}$ \\
\hline & $\begin{array}{l}\text { Bottom of the funnel: } 3 \text {. Conversion } \\
=\text { Lead generation }\end{array}$ & 3. Daily number of leads generated \\
\hline Control & Page views & Daily number of page views \\
\hline
\end{tabular}

of the check-out. This definition is required due to the nature of the automobile sector as a car cannot be purchased online for brands A to D. The closet measure of conversion will be drawing a lead, i.e., requesting a quote, a test drive, or further information. Focusing on online advertising channels, only the leads generated through one of these channels are considered. Leads generated on events or through postal mailings are not considered since they are not significant for the analysis of online channel effectiveness. For short-term elasticities, we refer to earlier stages of the conversion funnel, that is, organic search (as an indicator of interest) and direct traffic (consideration, intent).

We also use the number of page views as a control variable as it is strongly related to the number of conversions (Bucklin and Sismeiro 2003; Danaher et al. 2006; Danaher and van Heerde 2018).

Since budgets are set monthly while exposures like visits and leads are daily data, we obtained daily cost by dividing the respective cost by the number of days in a month. To include carryover effects, the current exposures are being replaced with the so-called "Adstock" variable (Leeflang et al. 2000). Adstock describes the lagged or prolonged advertising effect of a medium on a specific outcome in period $t$ (Danaher and van Heerde 2018). Adstock thus stands for the advertising effect of the previous day ( $t-1)$ impacting advertising effectiveness at time $t$ (i.e., the carryover effect). To assess the carryover effect of each medium on the lead generation, we assessed the decay parameter (e.g., Braun and Moe 2013, Dinner et al. 2014) in the interval $[0,1]$ through a nine-variate grid search in line with Danaher et al. (2008) and Danaher and van Heerde (2018). Per these previous studies, we restrict the possibilities to the values with two decimal points from 0 to 0.99 in increments of .01 , which requires $100^{9}$ decay parameter estimations. 


\section{Methodology}

\section{Model estimation steps}

We apply SVAR (Structural Vector Autoregression) modeling on our day-aggregate data as probit and logit models (e.g., Danaher and van Heerde 2018) only work with individual-level data. SVARs are a popular choice in previous literature on attribution modeling (e.g., Trusov et al. 2009; Wiesel et al. 2011) as the class of VAR models provide a method to investigate the dynamic character of attribution - when does an effect occur in time (e.g., Bronnenberg et al. 2000; Srinivasan et al. 2004)? However, VAR models do not take into account deterministic regressors and entail a complex interpretation as every variable is estimated as a dependent variable with the other variables being independent. SVARs instead focus on a quasi-causal link between defined independent and one dependent variable. Thereby, SVARs are "specifically designed to supplement sample-based information with managerial judgment and/or marketing theory" (Dekimpe and Hanssens, 2000, p. 185). We apply $R$ and the package vars (version 1.5-3) to estimate the SVARs for each of the four brands. The set of daily data allows us to test for temporal Granger causality (Granger 1969). Granger causality infers on the predictive causality of a time series, i.e., predictor variables explain the outcome more than randomly. A variable is revealed as endogenous ${ }^{1}$ when it is related in a Granger-causal manner to another variable (De Haan et al. 2016). As SVARS assumes trend stationarity (i.e., stationary - equal expectation values and variances over time - if a given trend would be removed), we apply the Kwiatkowski-PhillipsSchmidt-Shin (Kwiatkowski et al. 1992) test (KPSS) for trend stationarity in a second step. Further, we apply the Engle and Granger test (Engle and Granger 1987) to check for cointegration (i.e., that there is a long-term equilibrium of trends). The model fit is tested through Akaike information criterion (AIC) and Bayesian information criterion (BIC) while forecasting accuracy is evaluated by the mean absolute percentage error (MAPE) and the mean squared error (MSE) (Leeflang et al. 2015). The MAPE is estimated based on data from 334 days and validated through the data of the remaining 31 days. A model is considered appropriate if the tests (Granger, KPSS, Engle and Granger) are confirmed and no better model is found (minimum AIC, BIC, MAPE, MSE).

\section{Model selection}

With the results of these tests, the dynamic models are estimated. Monthly dummies are included in the model to cope with the seasonal effect. The reference month is set to February 2019 as this month is likely not affected by seasonal effects (no Christmas sales or Spring enrolments). We opt for the maximal parametrized model showing the lowest BIC and MAPE (see Table 4). This act coordinates with the findings of De Haan et al. (2016) regarding the higher effectiveness of non-restricted SVARs. The selected model accounts for channel effectiveness concerning lead generation, synergies between channels, carryover effects from advertising channels on the outcome as well as for the influencing character of the conversion funnel stages.

\footnotetext{
${ }^{1}$ A variable is endogenous when correlated with the error term (Dekimpe and Hanssens 2007).
} 
Table 4 Model fit test results per brand and outcome justifying the model selection

\begin{tabular}{lllllllll}
\hline Brand & Outcome & Granger & KPSS & Engle-Granger & AIC & BIC & MAPE & MSE \\
\hline A & Leads* & Y & Y & Y & 187.38 & 304.29 & 5.13 & .07 \\
B & Leads* & Y & Y & Y & 117.09 & 222.31 & 4.88 & .06 \\
C & Leads* & Y & Y & Y & 274.58 & 391.49 & 38.30 & 1.47 \\
D & Leads* & Y & Y & Y & 559.27 & 672.29 & 28.01 & 1.06 \\
\hline
\end{tabular}

Notes. Y = Test confirmed (yes) for Granger causality (Granger), stationarity of time-series (KPSS) and cointegration (Engle-Granger), *: Analyzed in the results section

\section{Results}

\section{Channel effectiveness}

To assess channel effectiveness concerning lead generation, the nine relevant advertising channels have been included in the model and linked to the outcome for each brand. Table 5 visualizes the parameter estimates that show a statistical significance above 5\%. An effect is considered essential when at least two brands show the same effect. For simplicity reasons and since the coefficients in all subsequent analyses are often very small, we denote positive (negative) coefficients with a positive (negative) sign.

The results highlight the superiority of FIC over CIC in terms of their effect on lead generation. The data indicates that paid search, social advertising, retargeting, and referrals have a significant and positive impact on lead generation. This result corroborates with Danaher and Dagger's paper (2013) stating that paid search is one of the most effective channels in online media with regard to conversion. However, this study does not confirm the fact that paid email is highly effective with regard to conversion. Instead, a negative impact of paid email on lead generation has been detected. The same applies for display ads, which have a significant negative or insignificant effect on the number of leads. This finding is supported by Xu, Duan, and Whinston (2014) whose research shows that display ads have a low direct effect on conversion. Interestingly, social advertising is very effective regarding Brand A and D. Their young target groups, as well as their informal communication towards them, could justify the appeal of advertising on social media to the consumers.

\section{Channel interaction effects}

To test for synergies between channels, interaction effects have been tested between each possible channel pair. Only the significant interactions (reducing information criteria) have been kept in the model ( $\mathrm{Li}$ and Kannan, 2014). Only one out of six significant interaction effects has been detected between a paid and owned channel, while the other describes two paid channels. This result agrees with the findings of Jayson, Block, and Chen (2018) that indicate higher effectiveness of both channels when used simultaneously.

The model highlighted some positive (synergy) and negative (interference) interaction effects, which must be taken into consideration when assessing channel effectiveness. For Brand A, retargeting enhances the effectiveness of email advertisements, as 
well as referrals that increase the effect of direct email on lead generation. However, paid search should not be combined with social advertising because they interfere with each other. This scenario concurs with the findings of Xu, Duan and Whinston (2014) on the topic of the indirect contribution of media on conversion. While Brand B shows no interactions, results for Brand $\mathrm{C}$ indicate synergies for display and paid email as well as for paid search and social advertising. A unique effect for Brand $\mathrm{C}$ is the interference of paid search and retargeting. Finally, for Brand D we found an opposite effect to Brand A regarding the now negative interaction of paid email and retargeting. Finally, display and social advertising interfere with generating leads. This is in line with previous studies (Berman and Katona 2013; Jerath et al. 2014) illustrating that Brand D targets consumer types differently and that display attracts more passive buyers. Social advertising targets more active information seekers. Both channels have their respective positive effects on lead generation but fail to work together in attracting one target group. The opposite seems true for Brand C, where both have a negative impact, but work well together.

\section{Carryover effects}

Table 6 reveals very high carryover effects (close to 1) for almost all channels. This results in a delayed effect of advertising exposures on lead generation. For Brands A to

Table 5 Advertising exposure, interaction and carryover effects on lead generation per brand

\begin{tabular}{|c|c|c|c|c|c|}
\hline Parameter & Channel & Brand A & Brand B & Brand C & Brand D \\
\hline \multirow[t]{9}{*}{ Main effect } & Display & $-* *$ & & $-* *$ & $+* * *$ \\
\hline & Paid search & $+* * *$ & $+* *$ & & \\
\hline & Video & & & & $-* * *$ \\
\hline & Paid email & $-* *$ & & $-* * *$ & $+* *$ \\
\hline & Social advertising & $+* * *$ & & $-* *$ & $+* * *$ \\
\hline & Direct email & $-*$ & & & \\
\hline & Retargeting & $-*$ & & $+* * *$ & $+^{*}$ \\
\hline & Referrals & $-*$ & & $+* * *$ & \\
\hline & Organic social & $-*$ & & & \\
\hline \multirow[t]{6}{*}{ Interaction effects } & Paid search $\mathrm{x}$ Social advertising & $-* * *$ & & $+* *$ & \\
\hline & Paid email $\mathrm{x}$ Retargeting & $+* *$ & & & $-* *$ \\
\hline & Direct email x Referrals & $+*$ & & & \\
\hline & Display x Paid email & & & $+* * *$ & \\
\hline & Paid search x Retargeting & & & $-* * *$ & \\
\hline & Display x Social advertising & & & & $-* * *$ \\
\hline Monthly dummies & None & August: -* & $\begin{array}{l}\text { October, } \\
\text { January: }+^{*}\end{array}$ & June: $+^{*}$ & \\
\hline Page views & None & & & & \\
\hline Range of carryover & All channels & $.94-.99$ & .99 & $.74-.99$ & $.02-.99$ \\
\hline
\end{tabular}

Notes: Dependent variable: Leads. Long-term effects depicted as positive $(+)$ or negative $(-)$. Blank: not significant. $p$-value $<.05: *, p$-value $<.01: * * p$-value $<.001: * * *$, only significant monthly dummies shown 


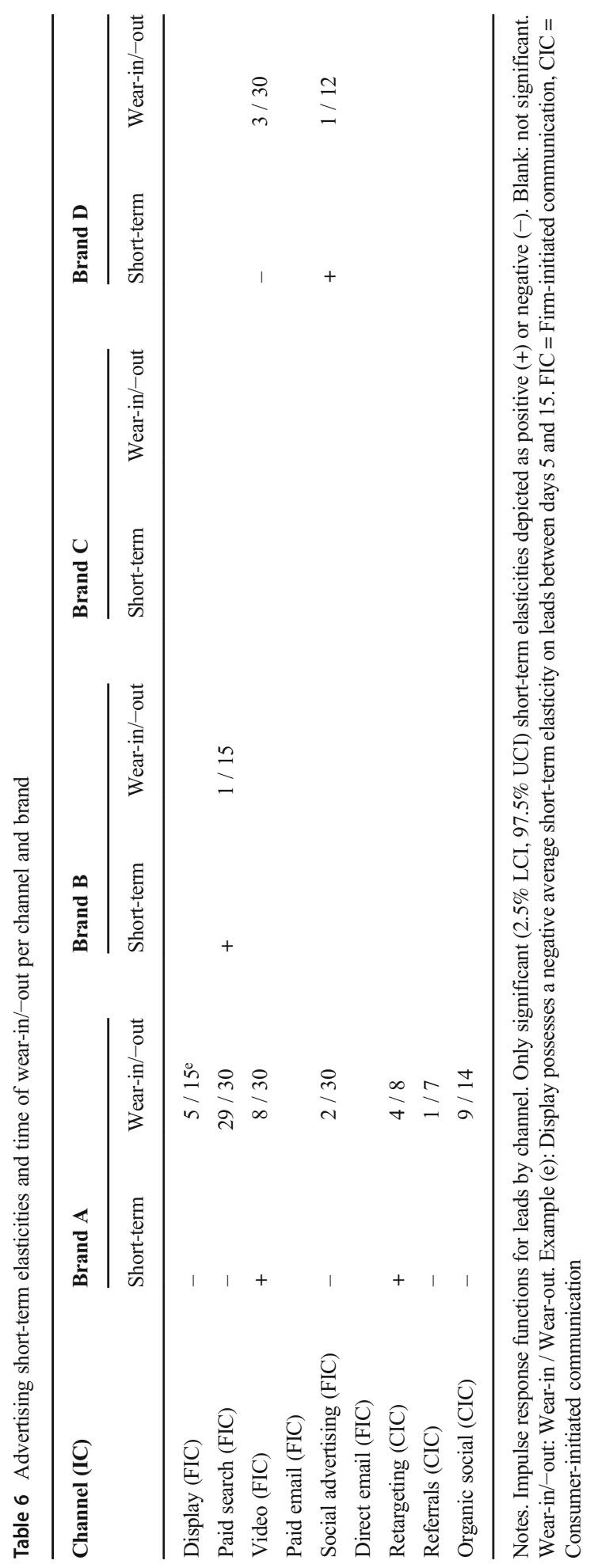




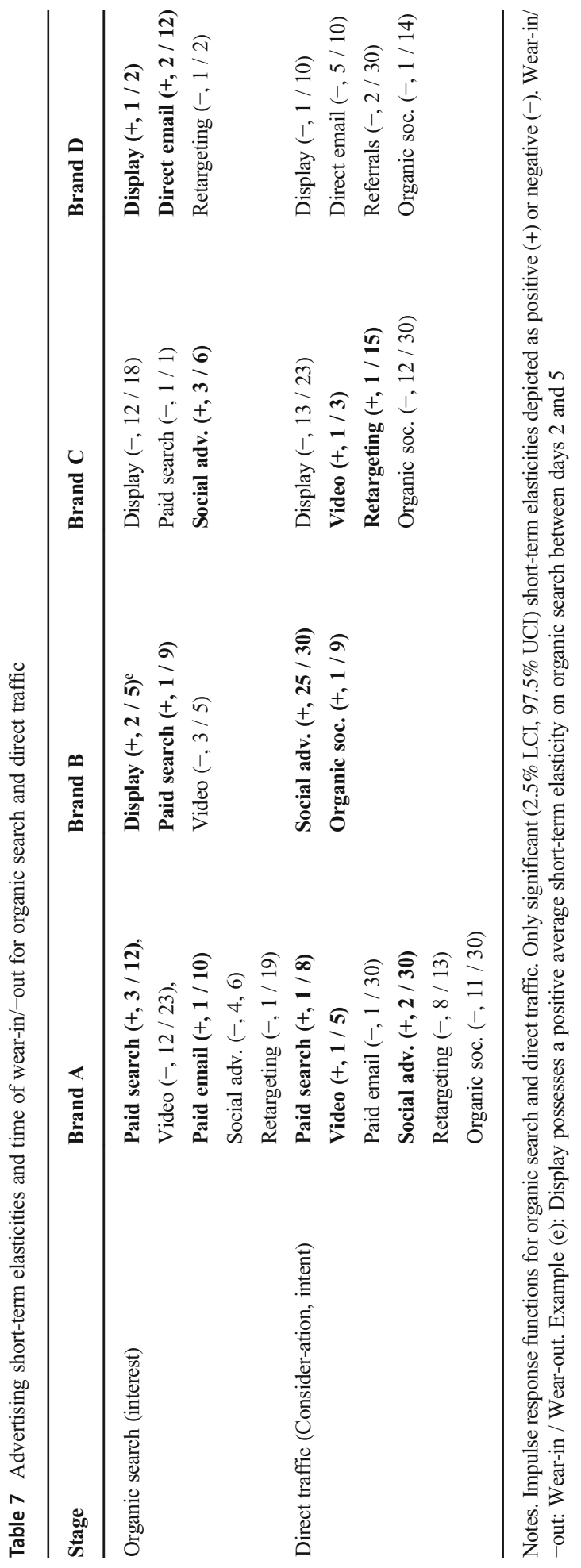


C, no carryover effect below .5 is found, i.e., the carryover effect from the previous day is constantly stronger than the exposure of the present day. For Brand D, only organic social (.02), direct email (.06) and social advertising (.31) yield substantially lower carryover effects. All other channels possess carryover effects of at least .84. This general theme seems to contradict previous research (e.g., Danaher and van Heerde 2018) but can be explained with the delayed response time to advertising in the present automobile sector compared to low-involvement FMCGs previously researched.

\section{Short-term effects}

An additional indicator of the delayed response time to advertising can be derived from the short-term elasticities (changes in an outcome due to a $1 \%$ variation in the predictor) estimated from impulse response functions of the SVAR models. In a nutshell, holding all other variables constant, these functions predict the change in elasticity over a certain period (30 days). A long-term elasticity describes the average effect over this period, while a short-term elasticity represents a time in this period when the elasticity is significantly positive (negative). The day this significance is achieved is termed "wear-in". The day significance is not achieved any longer is a "wear-out" (e.g., De Haan et al. 2016). Table 6 shows the short-term elasticities estimated.

It becomes evident that the wear-in and wear-out vary strongly among brands, channels, and outcomes. Only paid search for Brand A had a negative one-day shortterm effect. The other effects last from four days (retargeting, Brand A) to 28 days (social advertising, Brand A). This result contrasts with the findings of De Haan et al. (2016) that observed small short-term effects within a few days. Given that this study investigated sectors with a rather short customer journey and the present extended customer journey for the automobile sector, the present results are not unanticipated.

Moreover, paid media seems more effective than unpaid media as only $16.6 \%(2 / 12)$ of direct email, referrals and organic social as (virtually) cost-free channels but $33.3 \%$ (8/12) of display, paid search, video, paid email, social advertising and retargeting show significant short-term effects. These findings concur with previous research (e.g., Ghose and Todri-Adamopoulos 2016). Instead, firm- or consumer-initiated communication channels as a differentiation characteristic (Table 6) seem to have no influence (FIC: $29.2 \%$, CIC: $25.0 \%$ ).

We reran the impulse response functions for SVAR models of organic search (interest) and direct traffic (consideration, intent) as indicators of earlier stages in the advertising funnel. The results are briefly summarized in Table 7.

These supplementary results fit with previous literature indicating that paid channels dominate earlier stages of the conversion funnel (Li et al. 2017). Except for direct email (Brand D), organic search is mostly driven by display (Brand B and D), paid search (Brand $\mathrm{A}$ and $\mathrm{B}$ ), paid email (Brand $\mathrm{A}$ ) and social advertising (Brand C). For direct traffic (on model pages), paid channels also show positive short-term elasticities except for organic social (Brand B). Interestingly, apart from paid search for Brand A, effective channels switch completely from top-of-funnel to middle-of-funnel, that is, video (Brand $\mathrm{A}$ and $\mathrm{C}$ ), social advertising (Brand $\mathrm{A}$ and $\mathrm{B}$ ) as well as retargeting (Brand C) previously negatively or not effective become important. For Brand D, the brand with the smallest customer base and a young target group, consideration or interest cannot be gained on any channel, but lost with multiple ones (display, direct 
email, referrals, organic social). Here, social advertising is the lone hope to generate conversion in terms of lead generation which unexpectedly concurs with the research of Shao and Li (2011).

\section{Discussion and conclusion}

The question of optimal channel attribution cannot be solved by an unambiguous answer. Channel effectiveness depends on the desired outcome as well as the types of customers targeted. While some channels impact conversion positively, they could simultaneously have a negative effect on direct traffic, thereby reducing subsequent conversions. Thus, assessing channel effectiveness solely based on the performance of each channel on lead generation or the outcome sought for will most certainly lead to biases. This study revealed that paid search, social advertising, and retargeting have the most significant and positive impact on lead generation across the analyzed brands. However, focusing on interactions, different channels are revealed as effective. The aforementioned channels prove to interfere with each other. Both being effective ways of communication per se, overuse of the combination of paid search and retargeting might give the consumer the feeling of being pressured and hence have a counterproductive effect. Nevertheless, synergies favoring conversion were present for display and paid email. This finding is in line with earlier research (Ghose and Todri-Adamopoulos 2016; Xu et al. 2014). Based on Naik (2007) and Naik and Raman (2003), ineffective channels can support effective ones, thus positively contributing to the outcome. This has been found for retargeting and paid email. A major contribution of this research is that these synergy effects (as well as main effects) depend strongly on different brands and hence consumer audiences. While a synergy of retargeting and paid email is lead generating for one brand (Brand A), it is lead preventing for another (Brand D).

As discussed before, paid media perform well in the early stages of the conversion funnel (Raman et al. 2012). Despite negatively influencing lead generation by itself, paid email attracts the attention of the consumer in the awareness phase while retargeting improves conversion (Danaher et al. 2010; Hoban and Bucklin 2015). As channel effectiveness varies over time, attribution becomes dynamic. Consumers engage with different channels depending on their current funnel stage. While paid media is used effectively to attract new customers, social advertising unfolds its value close to conversion, as confirmed for two brands (Brand A and D). Due to the extensive, high-stake and high-involvement nature of an automotive decision-process (Duncan and Dempsey 2005) contrasting the low-involvement products dominating previous investigations, this dynamic becomes even more important in two ways. First, it has been demonstrated that a substantial carryover effect is present, leading to delayed responses to advertising (Hanssens et al. 1990). Second, most short-term effects (elasticities) are more prolonged than in categories such as FMCG (De Haan et al. 2016). Hence, both ways contribute to the need for carefully planned long-term marketing efforts.

Finally, comparing our results with heuristic attribution models (LTA) regarding allocation performance confirmed previous research (e.g., Danaher and van Heerde 2018) on the inefficiency of those heuristic models. The "last touch" does not allow investigating interactions, neither does it account for carryover effects. Our model 
approach, using SVAR with interaction effects based on carryover estimates and subsequently eyeing for short-term effects via impulse response functions allowed us to unravel the dynamics depicted before.

With the surge in new communication technologies and ways of tracking consumers throughout their path to conversion, researchers and practitioners have become increasingly interested in the effectiveness of advertising channels. The growing body of literature on the topic of channel attribution confirms this observation. The purpose of this study was to evaluate whether attribution modeling is a suitable solution to optimize advertising effectiveness in the automotive industry. To this end, we combined and extended two existing SVAR attribution models (Danaher and van Heerde 2018; De Haan et al. 2016) to review the validity of the insights generated in the state-of-the-art literature on attribution modeling. The formulated model is based on daily data from a multinational car manufacturer over one year on channel traffic and investment per channel. Hereby, we confirmed that the commonly used heuristic attribution models strongly under- and over-estimate the effectiveness of certain channels due to their disregarding of these key factors, heavily impacting channel effectiveness ( $\mathrm{Li}$ and Kannan 2014). These attribution models do not take into consideration the dynamic aspect of channel effectiveness essential for correct allocation of budget (Raman et al. 2012). We offered empirical evidence of strong carryover effects of online advertising channels as well as lasting short-term effects in a high-stake, high-involvement context.

Further, this study showed that the simultaneous use of channels can either enhance their effectiveness (synergetic effect) or interfere with the outcome if both are negatively linked with each other (interference). Finally, channel effectiveness is conditional on the target audience and conversion funnel. While some media forms attract new consumers by creating brand awareness, others convert consumers to customers by stimulating the use of other touchpoints thus indirectly impacting outcome (Xu et al. 2014). Depending on the outcome and audience, marketers should aim for a distinctive channel mix.

To conclude, data-based multichannel attribution enables marketers to evaluate the distinct and joint contribution of available advertising channels to a specific outcome. By assessing this contingent channel effectiveness, a valuable foundation for budget allocation is created. Especially in the automotive industry, characterized by a lengthy decision-making process, attribution modeling is a way to incorporate the complex time-varying aspects of channel effectiveness concerning media planning and budgeting.

\section{Managerial implications}

Possibly discouraging at first, this research shows an even more complex picture of advertising effectiveness. Previously introduced complex statistical models such as Logit- or Probit-regression, Vector Autoregression (VAR), and today SVARs capture more and more dynamics. Taking this to a new level accounting for multiple channels and brands in a high-involvement sector yielded even more dynamics. Consequentially, the quest for heuristics and "silver bullets" seems to be at its end. Investigating single channels per se (and not interactions), relying on the long-term effectiveness of those channels (and not short-term effects), assuming immediate consequences (and not lagged effects) or expecting comparable effects in a single sector (not even in all 
brands of an umbrella brand) are the cardinal biases for practitioners. The distinct effects found for the four brands depicted, contingent on the level of the conversion funnel, are the key take-home message of this paper. Different (sub-)brands with unalike brand positioning, market shares and audiences expectedly require unique advertising mixes.

The lone solution to this dynamism issue hence can be seen in better market research, better and more in-time data, better measures and models to work with. Relying on LPA or any other heuristic attribution model decreases effectiveness and efficiency and hence leads to misused budgets. Since the dynamism issue accompanies high uncertainty of budget allocation and advertising monitoring, this even provides new leverage for research-close practitioners, advisors, and firms, striving for a marketing advantage through better budget utilization and potentially relevant targets such as increased brand awareness and customer engagement. This seems particularly true for high-involvement, high-stake product sectors.

\section{Limitations and recommendations for further research}

While contributing new insights to the research on channel attribution, this study has several limitations that serve as fertile avenues for further research.

First, individual-level data instead of aggregate data would have given a more precise look into the impact of advertising effectiveness. Moreover, daily data could have allowed better detection of additional patterns, e.g., weekend effects. However, managers use pulsing media schedules, i.e., not continuously and regularly investing in the same channels. In that case, SVARs are not appropriate since they assume stationarity - constant investments (Sasieni 1971). We recommend investigations with more granular data.

Second, contextual aspects like competition, new product launches or facelifts relevant in the automotive industry could not have been captured as restrictions in confidentiality and anonymity were and are still present. Additionally, information about the four brands highlighting circumstances of the one year of data cannot be made public for the same reasons. Equally, comparisons between brands were not possible as this would require more detailed information that was prevented by brand anonymity. Subsequent research in less restrictive sectors is welcomed to verify the present results.

Third, the found carryover effects for all brands (ranging from .74 and .99) indicate that advertising expenditures have a heightened lagged effect. Whether this is due to the nature of a high-involvement sector like the automotive industry (as assumed) or a statistical remedy cannot be investigated with a single dataset. Replications, particularly in other high-involvement sectors such as real estate, long-lasting consumer electronics or furniture can fill this void. We also acknowledge that De Haan et al. (2016) and Pauwels et al. (2016) investigated those sectors (Table 1) but did not discuss the highinvolvement aspect. Specific reinvestigations may contribute to this research avenue.

Fourth, the conversion funnel investigated regarding long-term and short-term effects in attribution was not incorporated in a nested or multi-level manner. That is, models explaining lead generation, organic search and direct traffic were estimated separately. The same is true for the four brands. Hence, correlations between those 
outcome variables could not be considered. To the best of our knowledge, such a modeling approach is not currently available. We welcome research, both contributing methodologically and in an attribution context.

Fifth, we focused solely on lead generation for the very reason that cars cannot be purchased online and strongly require physical interaction (e.g., test drives). This, however, may change soon, allowing actual transactions to serve as a variable of the conversion stage. So far, we also consent that a generated lead (requesting a quote like a test drive or supplementary information about the car) does not equate with an eventual transaction. Future research regarding this matter is welcomed as well.

Finally, despite the importance of the LTA as the most often used attribution model (Danaher and van Heerde 2018) to date, companies such as Google, Visual IQ, and Bizible have heard the call for more advanced attribution modeling as well as allocation optimization. Their software goes beyond the heuristic attribution model of LTA investigated in the present paper. We thus need to restrict our comparisons to this most simplistic model and encourage subsequent research to investigate elaborated methods used in marketing practice.

Acknowledgements The dataset used in this paper was provided by Accenture Interactive Germany and confidentiality protected by a non-disclosure agreement between the authors and the company, particularly anonymizing the brands owned by a client of the company.

Open Access This article is licensed under a Creative Commons Attribution 4.0 International License, which permits use, sharing, adaptation, distribution and reproduction in any medium or format, as long as you give appropriate credit to the original author(s) and the source, provide a link to the Creative Commons licence, and indicate if changes were made. The images or other third party material in this article are included in the article's Creative Commons licence, unless indicated otherwise in a credit line to the material. If material is not included in the article's Creative Commons licence and your intended use is not permitted by statutory regulation or exceeds the permitted use, you will need to obtain permission directly from the copyright holder. To view a copy of this licence, visit http://creativecommons.org/licenses/by/4.0/.

\section{References}

Anderl, E., Becker, I., von Wangenheim, F., \& Schumann, J. H. (2016). Mapping the customer journey: Lessons learned from graph-based online attribution modeling. International Journal of Research in Marketing, 33(3), 457-474.

Anderl, E., Schumann, J. H., \& Kunz, W. (2015). Helping firms reduce complexity in multichannel online data: A new taxonomy-based approach for customer journeys. Journal of Retailing, 92(2), 185-203.

Ansari, A., Mela, C. F., \& Neslin, S. A. (2008). Customer channel migration. Journal of Marketing Research, $45(1), 60-76$.

Bass, F. M. (1969). A simultaneous equation regression study of advertising and sales of cigarettes. Journal of Marketing Research, 6(3), 291-300.

Batra, R., \& Keller, K. L. (2016). Integrating marketing communications: New findings, new lessons and new ideas. Journal of Marketing, 80(6), 122-145.

Berman, R., \& Katona, Z. (2013). The role of search engine optimization in search marketing. Marketing Science, 32(4), 533-678.

Bonfrer, X., \& Drèze, A. (2009). Moving from customer lifetime value to customer equity. Quantitative Marketing and Economics, 7(3), 289-320.

Bowman, D., \& Narayandas, D. (2001). Managing customer-initiated contacts with manufacturers: The impact on share of category requirements and word-of-mouth behavior. Journal of Marketing Research, 38(3), 281-297. 
Braun, M., \& Moe, W. W. (2013). Online display advertising: Modeling the effects of multiple Creatives and individual impression histories. Marketing Science, 32(5), 753-767.

Briggs, R., Krishnan, R., \& Borin, N. (2005). Integrated multichannel communication strategies: Evaluating the return on marketing objectives-The case of the 2004 ford F-150 launch. Journal of Interactive Marketing, 19(3), 81-90.

Bronnenberg, B. J., Vijay, M., \& Vanhonacker, W. R. (2000). The emergence of market structure in new repeat-purchase categories: The interplay of market share and retailer distribution. Journal of Marketing Research, 37(1), 16-31.

Broussard, G. (2016). Enriching media data: A special report from the U.S. Coalition of Innovative Media Measurement (CIMM): Quality is key requisite for maximizing return on advertising investment. Journal of Advertising Research, 56(1), 25-38.

Bruce, N., Foutz, N. Z., \& Kolsarici, C. (2012). Dynamic effectiveness of advertising and word of mouth in sequential distribution of new products. Journal of Marketing Research, 49(4), 469-486.

Bucklin, R. E., \& Sismeiro, C. (2003). A model of web site browsing behavior estimated on clickstream data. Journal of Marketing Research, 40(3), 249-267.

Bushman, B. J., \& Bonacci, A. M. (2002). Violence and sex impair memory for television ads. Journal of Applied Psychology., 87(3), 557-564.

Chan, T. Y., Wu, C., \& Xie, Y. (2011). Measuring the lifetime value of customers Acquired from Google search advertising. Marketing Science, 30(5), 837-850.

Chang, Y., \& Thorson, E. (2004). Television and web advertising synergies. Journal of Advertising, 33(2), 75-84.

Chatterjee, P. (2012). The role of varying information quantity in ads on immediate and enduring cross-media synergies. Journal of Marketing Communications, 18, 217-240.

Chatterjee, P., Hoffman, D. L., \& Novak, T. P. (2003). Modeling the clickstream: Implications for web-based advertising efforts. Marketing Science, 22(4), 520-541.

Crestodina, A. (2019). Content and conversion - When stakes are high, Marketing News, February, 24-25.

Danaher, P. J., \& Dagger, T. S. (2013). Comparing the relative effectiveness of advertising channels: A case study of a multimedia blitz campaign. Journal of Marketing Research, 50(4), 517-534.

Danaher, P. J., \& van Heerde, H. J. (2018). Delusion in attribution: Caveats in using attribution for multimedia budget allocation. Journal of Marketing Research, 55(5), 667-685.

Danaher, P. J., Lee, J., \& Kerbache, L. (2010). Optimal internet media selection. Marketing Science, 29(2), 336-347.

De Haan, E., Wiesel, T., \& Pauwels, K. (2016). The effectiveness of different forms of online advertising for purchase conversion in a multiple-channel attribution framework. International Journal of Research in Marketing, 33(1), 491-507.

Dekimpe, M. G., \& Hanssens, D. M. (2000). Time-series models in marketing: Past, present and future. International Journal of Research in Marketing, 17(2-3), 183-193.

Dekimpe, M. G., \& Hanssens, D. M. (2007). Advertising response models. In: G. J. Tellis \& Ambler ,T. (Eds.). Handbook of advertising (pp. 247-263), London: Sage.

Deloitte (2018). Deloitte global automotive consumer study. Deloitte. https://www2.deloitte. com/content/dam/Deloitte/de/Documents/consumer-industrial-products/2018_GACS_Data\%20Deck_ Germany.pdf. Accessed 19 June 2019.

Dijkstra, M., Buijtels, H., \& Van Raaij, W. F. (2005). Separate and joint effects of medium type on consumer responses: A comparison of television, print, \& the internet. Journal of Business Research, 58(3), 377386.

Dinner, I., van Heerde, H. J., \& Neslin, S. A. (2014). Driving online and offline sales: The cross-channel effects of traditional, online display, \& paid search advertising. Journal of Marketing Research, 51(5), $527-545$.

Doctorow, D., Hoblit, R., \& Sekhar, A. (2009). Measuring marketing: 721 McKinsey global survey results. McKinsey Quarterly, 12(1), 1-3.

Duncan, H. J., \& Dempsey, W. A. (2005). Comparing the current effects and carryover of national-, regional-, \& local-sponsor advertising. Journal of Advertising Research, 45(1), 60-72.

eMarketer (2019). Digital advertising spending worldwide from 2015 to 2020 (in billion U.S. dollars). Statista. https://www-statista-com.ezproxy.hwr-berlin.de/statistics/237974/online-advertising-spendingworldwide/. Accessed 19 June 2019.

Engle, R. F., \& Granger, C. W. J. (1987). Co-integration and error correction: Representation, estimation, \& testing. Econometrica, 55(2), 251-276. 
Fulgoni, G., \& Lipsman, A. (2014). Digital game changers: How social media will help usher in the era of Mobile and multi-platform campaign-effectiveness measurement. Journal of Advertising Research, 54(1), 11-16.

Gatignon, H., \& Hanssens, D. M. (1987). Modeling marketing interactions with application to Salesforce effectiveness. Journal of Marketing Research, 24(3), 247-257.

Ghose, A., \& Todri-Adamopoulos, V. (2016). Toward a digital attribution model: Measuring the impact of display advertising on online consumer behavior. MIS Quarterly, 40(4), 889-910.

Ghose, A., \& Yang, S. (2009). An empirical analysis of search engine advertising: Sponsored search in electronic markets. Management Science, 55(20), 1605-1622.

Goldenberg, J., Oestreicher-Singer, G., \& Reichman, S. (2012). The quest for content: How user-generated links can facilitate online exploration. Journal of Marketing Research, 49(4), 452-468.

Gopinath, S., Thomas, J. S., \& Krishnamurthi, L. (2014). Investigating the relationship between the content of online word of mouth, advertising, \& brand performance. Marketing Science, 33(2), 241-258.

Granger, C. W. J. (1969). Investigating causal relations by econometric models and cross-spectral methods. Econometrica, 37(3), 424-438.

Gupta, S., \& Steenburgh, T. (2008). Allocating marketing resources. In R. A. Kerin \& R. O’Regan (Eds.), Marketing mix decisions: New perspectives and practices (pp. 3-37). Chicago: American Marketing Association.

Hauser, J. R., \& Wernerfelt, B. (1990). An evaluation cost model of consideration sets. Journal of Consumer Research, 16(4), 393-408.

Hoban, P. R., \& Bucklin, R. E. (2015). Effects of internet display advertising in the purchase funnel: Modelbased insights from a randomized field experiment. Journal of Marketing Research, 52(3), 375-393.

Howard, J. A., \& Sheth, J. N. (1969). The theory of buyer behavior. New York: Wiley.

Hu, Y., Lodish, L. M., \& Krieger, A. M. (2007). An analysis of real world TV advertising tests: A 15 year update. Journal of Advertising Research, 47(3), 341-353.

Jansen, B. J., \& Schuster, S. (2011). Bidding on the buying funnel for sponsored search and keyword advertising. Journal of Electronic Commerce Research, 12(1), 1-18.

Jayson, R., Block, M. P., \& Chen, Y. (2018). How synergy effects of paid and digital owned media influence brand sales considerations for marketers when balancing media spend. Journal of Advertising Research, 58(1), 77-89.

Jedidi, K., Mela, C. F., \& Gupta, S. (1999). Managing advertising and promotion for long-run profitability. Marketing Science, 18(1), 1-22.

Jerath, K., Ma, L., \& Park, J.-H. (2014). Consumer click behavior at a search engine: The role of keyword popularity. Journal of Marketing Research, 51(4), 480-486.

Kannan, P. K., Reinartz, W., \& Verhoef, P. C. (2016). The path to purchase and attribution modeling: Introduction to special section. International Journal of Research in Marketing, 33(3), 449-456.

Klever, A. (2009). Behavioural targeting: An online analysis for efficient media planning? Hamburg: Diplomica Publishing.

Kotler, P., \& Armstrong, G. (2011). Principles of marketing. Upper Saddle River, NJ: Prentice Hall.

Krishnamurthi, L., \& Papatla, P. (2003). Accounting for heterogeneity and dynamics in the loyalty-Price sensitivity relationship. Journal of Retailing, 79(2), 121-135.

Kuehn, A. A. (1962). Consumer brand choices: A learning process? Journal of Advertising Research, 2(4), $10-17$.

Kumar, A., Bezawada, R., Rishika, R., Janakiraman, R., \& Kannan, P. (2016). From social to sale: The effects of firm generated content in social media on customer behavior. Journal of Marketing, 80(1), 7-25.

Kwiatkowski, D., Phillips, P. C. B., Schmidt, P., \& Shin, Y. (1992). Testing the null hypothesis of stationarity against the alternative of a unit root: How sure are we that economic time series have a unit root? Journal of Econometrics, 54(1-3), 159-178.

Lambrecht, A., \& Tucker, C. E. (2013). When does retargeting work? Information specificity in online advertising. Journal of Marketing Research, 50(5), 561-576.

Leeflang, P. S. H., Wieringa, J. E., Bijmolt, T. H. A., \& Pauwels, K. H. (2015). Modeling markets: Analyzing marketing phenomena and improving marketing decision making. New York: Springer.

Leeflang, P. S. H., Wittink, D. R., Wedel, M., \& Naert, P. A. (2000). Building models for marketing decisions. Boston: Kluwer Academic.

Lemon, K. N., \& Nowlis, S. M. (2002). Developing synergies between promotions and Brands in Different Price-Quality Tiers. Journal of Marketing Research, 39(May), 171-185.

Leone, R. P. (1995). Generalizing what is known about temporal aggregation and advertising carryover. Marketing Science, 14(3), 141-150. 
Leone, R. P., \& Schultz, R. L. (1980). A study of marketing generalizations. Journal of Marketing, 44(1), 1018.

Lewis, R. A., \& Rao, J. M. (2015). The unfavorable economics of measuring the returns to advertising. Quarterly Journal of Economics, 130(4), 1941-1973.

Li, H., \& Kannan, P. K. (2014). Attributing conversions in a multichannel online marketing environment: An empirical model and a field experiment. Journal of Marketing Research, 51(1), 40-56.

Lin, C., Venkataraman, S., \& Jap, S. D. (2013). Media multiplexing behavior: Implications for targeting and media planning. Marketing Science, 32(2), 310-324.

Luo, X., \& Donthu, N. (2006). Marketing's credibility: A longitudinal investigation of marketing communication productivity and shareholder value. Journal of Marketing, 70(3), 70-91.

Mahajan, V., Bretschneider, S. I, \& Bradford, J. W. (1980). Feedback approaches to modeling structural shifts in market response. Journal of Marketing, 44(1), 71-80.

Manchanda, P., Dubé, J.-P., Goh, K. Y., \& Chintagunta, P. K. (2006). The effect of banner advertising on internet purchasing. Journal of Marketing Research, 43(1), 98-108.

MSI (2016). Marketing Science Institute research priorities 2014-2016. MSI. http://www.msi. org/research/2014-2016-research-priorities/. Accessed 19 June 2019.

Mehta, N., Rajiv, S., \& Srinivasan, K. (2003). Price uncertainty and consumer search: A structural model of consideration set formation. Marketing Science, 22(1), 58-84.

Moe, W. W., \& Fader, P. S. (2004). Dynamic conversion behavior at e-commerce sites. Management Science, 50(3), 326-335.

Naik, P. A., \& Peters, K. (2009). A hierarchical marketing communications model of online and offline media synergies. Journal of Interactive Marketing, 23(4), 288-299.

Naik, P. A., \& Raman, K. (2003). Understanding the impact of synergy in multimedia communications. Journal of Marketing Research, 40(4), 375-388.

Nisar, T. M., \& Yeung, M. (2017). Attribution modeling in digital advertising. Journal of Advertising Research, 58(4), 399-413.

Nunes, P. F., \& Merrihue, J. (2007). The continuing power of mass advertising. MIT Sloan Management Review, 48(2), 63-69.

Nyilasy, G., King, K. W., \& Reid, L. N. (2011). Checking the pulse of print media: Fifty years of newspaper and magazine advertising research. Journal of Advertising Research, 51(1), 167-181.

Osinga, E. C., Leeflang, P. S. H., Srinivasan, S., \& Wieringa, J. E. (2011). Why do firms invest in consumer advertising with limited sales response? A shareholder perspective. Journal of Marketing, 75(1), 109124.

Parsons, T. (1974). Review of Harold J. Bershady: Ideology and social knowledge. Sociological Inquiry, 44(3), 215-221.

Pauwels, K., Demirci, C., Yildirim, G., \& Srinivasan, S. (2016). The impact of brand familiarity on online and offline media synergy. International Journal of Research in Marketing, 33(4), 739-753.

Raman, K., Mantrala, M. K., Sridhar, S., \& Tang, Y. E. (2012). Optimal resource allocation with time-varying marketing effectiveness, margins and costs. Journal of Interactive Marketing, 26(1), 43-52.

Reid, M., Luxton, S., \& Mavondo, F. (2005). The relationship between integrated marketing communication, market orientation, \& brand orientation. Journal of Advertising, 34(4), 11-23.

Rutz, O. J., \& Bucklin, R. E. (2011). From generic to branded: A model of spillover in paid search advertising. Journal of Marketing Research, 48(1), 87-102.

Sasieni, M. W. (1971). Optimal advertising expenditure. Management Science, 18(4), part II, 64-72.

Schumann, J. H., von Wangenheim, F., \& Groene, N. (2014). Targeted online advertising: Using reciprocity appeals to increase acceptance among users of free web services. Journal of Marketing, 78(1), 59-75.

Schweidel, D. A., \& Moe, W. W. (2014). Listening in on social media: A joint model of sentiment and venue format choice. Journal of Marketing Research, 51(4), 387-402.

Sethuraman, R., Tellis, G. J., \& Briesch, R. A. (2011). How well does advertising work? Generalizations from meta-analysis of brand advertising Elasticities. Journal of Marketing Research, 48(3), 457-471.

Shankar, V., Inman, J. J., Mantrala, M., Kelley, E., \& Rizley, R. (2011). Innovations in shopper marketing: Current insights and future research issues. Journal of Retailing, 87, 29-41.

Shao, X., \& Li, L. (2011). Data-driven multi-touch attribution models. Proceedings of the ACM Conference on Knowledge Discovery and Data Mining, 258-264.

Smith, T. M., Gopalakrishna, S., \& Chatterjee, R. (2006). A three-stage model of integrated marketing communications at the marketing-sales interface. Journal of Marketing Research, 43(4), 564-579.

Srinivasan, S., Pauwels, K., Hanssens, D., \& Dekimpe, M. G. (2004). Do promotions benefit manufacturers, retailers, or both? Management Science, 50(5), 617-629. 
Steenkamp, J. B., \& Geyskens, I. (2006). How country characteristics affect the perceived value of web sites. Journal of Marketing, 70(3), 136-150.

Stern, B. L., \& Resnik, A. J. (1991). Information content in television advertising: A replication and extension. Journal of Advertising Research, 31(3), 36-46.

Trusov, M., Bodapati, A. V., \& Bucklin, R. E. (2010). Determining influential users in internet social networks. Journal of Marketing Research, 47(4), 643-658.

Trusov, M., Bucklin, R. E., \& Pauwels, K. (2009). Effects of word of mouth versus traditional marketing: Findings for an internet social networking site. Journal of Marketing, 73(5), 90-102.

Tsao, J. C., \& Sibley, S. D. (2004). Displacement and reinforcement effects of the internet and other media as sources of advertising information. Journal of Advertising Research, 44(1), 126-142.

Valentini, S., Montaguti, E., \& Neslin, S. A. (2011). Decision process evolution in customer channel choice. Journal of Marketing, 75(6), 72-86.

Van den Bulte, C., \& Wuyts, S. (2007). Social networks and marketing. Cambridge, Massachusetts: Marketing Science Institute.

Wiesel, T., Pauwels, K., \& Arts, J. (2011). Marketing's profit impact: Quantifying online and off-line funnel progression. Marketing Science, 30(4), 604-611.

Wood, L. A., \& Poltrack, D. F. (2015). Measuring the long-term effects of television advertising. Journal of Advertising Research, 55(2), 123-131.

Xu, L., Duan, J. A., \& Whinston, A. (2014). Path to purchase: A mutually exciting point process model for online advertising and conversion. Management Science, 60(6), 1392-1412.

Zantedeschi, D., Feit, E. M., \& Bradlow, E. T. (2016). Measuring Multi-Channel advertising effectiveness using consumer-level advertising response data measuring Multi-Channel advertising effectiveness using consumer. Management Science, 63(8), 2706-2728.

Zenith (2019). Distribution of global advertising spending in 2021, by media. Statista. https://www-statistacom.ezproxy.hwr-berlin.de/statistics/269333/distribution-of-global-advertising-expenditure/. Accessed 19 June 2019.

Publisher's note Springer Nature remains neutral with regard to jurisdictional claims in published maps and institutional affiliations.

\section{Affiliations}

\section{Thomas Niemand ${ }^{1}$ - Sascha $\mathrm{Kraus}^{2}$ - Sophia Mather ${ }^{3}$ - Antonio C. Cuenca-Ballester ${ }^{4}$}

1 Institute of Management and Economics, Clausthal University of Technology, Albrecht-von-GroddeckStrasse 7, Clausthal-Zellerfeld 38678, Germany

2 Durham University Business School, Durham University, Mill Hill Lane, Durham DH1 3LB, UK

3 ESCE International Business School, 10 Rue Sextius Michel, 75015 Paris, France

4 Universitat de València, Av. de Blasco Ibáñez, 13, 46010 València, Spain 